\title{
Direct Measurement of Microporosity and Molecular Accessibility in Stöber Spheres by Adsorption Isotherms
}

Judit Farrando-Pérez, Cefe López, Joaquín Silvestre-Albero*, Francisco Gallego-Gómez*

Correspondence e-mail: francisco.gallego@icmm.csic.es, joaquin.silvestre@ua.es

\begin{abstract}
The microporous nature of monodisperse Stöber silica spheres is demonstrated in the literature, although usually via indirect evidence. Contradictorily, there also exist numerous reports of nonporosity based on conventional $\mathrm{N}_{2}$ adsorption isotherms, leading to a confusing scenario and questioning the evaluation methodology. Thus, there is the strong need of straight measure of microporosity in Stöber spheres, at best by available adsorption techniques, which must be further directly confronted with the standard nitrogen method. Here, for the first time, microporosity detection by $\mathrm{N}_{2}$ and $\mathrm{CO}_{2}$ adsorption are compared in Stöber spheres. We demonstrate that $\mathrm{CO}_{2}$ isotherms at $273 \mathrm{~K}$ allows direct detection and quantification of the microporosity (about $0.1 \mathrm{~cm}^{3} / \mathrm{g}$ in our samples), while $\mathrm{N}_{2}$ at $77 \mathrm{~K}$ cannot probe adequately the internal volume. We also show that a large amount of water fills the micropores under usual ambient conditions, also revealing the presence of small mesoporosity. Thus, the porous nature of Stöber spheres is investigated by a simple combination of adsorption isotherms, and the different accessibility of $\mathrm{N}_{2}, \mathrm{CO}_{2}$ and $\mathrm{H}_{2} \mathrm{O}$ molecules are discussed. We emphasize the inadequacy of standard $\mathrm{N}_{2}$ isotherms for micropore detection in Stöber silica, as the access of nitrogen molecules at cryogenic temperatures is kinetically restricted and may lead to erroneous
\end{abstract}


conclusions. Instead, we propose $\mathrm{CO}_{2}$ isotherms as a simple and direct means for evaluation of microporosity.

\section{INTRODUCTION}

The Stöber-Fink-Bohn (abbr. Stöber or SFB) process $^{1}$ is the most-widely employed method for fabrication of monodisperse silica beads. It provides a low-temperature, cost-effective synthesis of colloidal spheres of controlled size with many scientific and industrial uses, such as chromatography, ${ }^{2}$ catalysis, ${ }^{3,4}$ biological,$^{5-9}$ drug release, ${ }^{10,11}$ colloidal assemblies, ${ }^{12,13}$ sieves, ${ }^{14,15}$ fillers ${ }^{16,17}$ or as templates. ${ }^{10,18-21}$ Extensive investigations have been made on particle nucleation and growth mechanisms of Stöber spheres, ${ }^{22-26}$ size control, ${ }^{27-31}$ structural properties, ${ }^{32-35}$ etc. Paradoxically, after decades of research and practical application, main aspects of Stöber spheres are still not well understood, revealing that, despite apparent simplicity, they are actually a very complex system with structural and chemical features difficult to apprehend.

In particular, a fundamental characteristic such as the presence or not of microporosity in the spheres (and its convenient experimental evaluation) is still controversial, and even recent data found in the literature are inconsistent. $\mathrm{N}_{2}$ adsorption at $77 \mathrm{~K}$ up to atmospheric pressure is the most standard technique for the characterization of the porous structure in inorganic solids, ${ }^{36}$ providing information about microporosity (pores $<2 \mathrm{~nm}$ ) and mesoporosity (from 2 to $50 \mathrm{~nm}$ ) of the evaluated sample. However, it is frequently overlooked that such assumption is only valid if no pore access restrictions concur. In particular, this aspect regarding Stöber spheres has already been discussed by some authors, ${ }^{23,33-35,37-40}$ concluding that nitrogen molecules at 
cryogenic temperatures typically have restricted accessibility to Stöber micropores, leading to unreliable characterization. Only exceptionally, significant internal volume has been detected in SFB spheres by $\mathrm{N}_{2}$ adsorption, ${ }^{40-44}$ which must be ascribed to an unusually accessible micropore structure. ${ }^{40,44}$ (Similar difficulties have also been found in $\mathrm{Ar}^{25,40,45} \mathrm{Kr},{ }^{23,41}$ or $\mathrm{Xe}^{23}$ adsorption isotherms). Alternatively to gas adsorption, Stöber microporosity has been indirectly deduced from the specific surface area, determined by different techniques, such as small-angle X-ray scattering $(\mathrm{SAXS}),{ }^{39}$ nuclear magnetic resonance (NMR), ${ }^{35}$ thermogravimetry (TGA), ${ }^{34,41,45,46}$ titration $^{38,47}$ and liquid sorption, ${ }^{39,48}$ or from the spheres density. ${ }^{22,27,28,41,49,50}$ These studies constitute experimental proof that significant microporosity is connatural to Stöber spheres, including those with larger diameters (> $100 \mathrm{~nm}$ ) and considering usual fabrication-dependent differences.

Nevertheless, the aforementioned considerations are often ignored and $\mathrm{N}_{2}$ adsorption has habitually been used, even recently, for pore and surface characterization of Stöber and Stöbermodified particles without questioning its validity. ${ }^{6,19,30,42,43,51-58}$ On such basis, many studies (and manufacturers) claim no (or very low) microporosity in Stöber spheres. $^{3-5,7-10,17,28,29,51,59-61}$ To our knowledge, Stöber spheres (without modified synthesis or post-treatment) have never been demonstrated as nonporous by other means, so these results should be considered, at least, inconclusive on account of the previous experimental evidence of microporosity. Such inconsistency in the literature, embracing contemporary reports, manifests the lack of a well-established methodology for characterization of porosity with complex accessibility, as that of Stöber spheres.

The knowledge of internal pore volume is indispensable to rationalize the properties of Stöber spheres and better know their functionalities. The pore characteristics define basic 
magnitudes, such as the refractive index or the mass density, which are crucial to understand many systems integrating Stöber silica. This comprehension also involves identifying the accessibility of molecules that are able to be effectively adsorbed and fill the internal volume, which is relevant for e.g. correct spheres characterization by dynamic light scattering and pycnometry. ${ }^{49}$ More importantly, this aspect critically determines the functionalities of Stöber spheres in a variety of scientific and technological applications, such as molecular and ion sieving, ${ }^{14,15,23,38,47,48}$ charge control ${ }^{62-64}$ and $\mathrm{pH}$-sensing. ${ }^{11} \mathrm{SFB}$ spheres are also employed as model microsystems, ${ }^{56,63-65}$ and as "non-porous" reference in biological assays, ${ }^{5,7,9-11,21,55}$ so that the acquaintance of their actual porosity and accessibility is essential to avoid current misleading assumptions.

Molecular accessibility in Stöber silica is still poorly understood to-date. In particular, very few studies have investigated the ability of water to penetrate and fill the Stöber micropores, ${ }^{32,39,59,66,67}$ in spite of the usual presence of surrounding moisture or imbibing liquid water. Thus, the spheres charge, ${ }^{62,63}$ mechanical properties ${ }^{50}$ or aging $^{35,44}$, may depend on the soaking of the inner volume. More generally, the presence and behavior of water inside Stöber particles at given ambient conditions may greatly influence the performance of a system, of which they are part. A prominent example are artificial silica opals, which are nanostructured photonic crystals customarily made by self-assembled Stöber spheres. ${ }^{68}$ As periodically dielectric structures, opals exhibit a photonic response dependent on the refractive index of both the sphere and the medium filling the interparticle space (void). Specifically, it is known that the photonic performance of silica opals is directly affected by the ability of Stöber spheres to adsorb water from the surrounding moisture and its distribution. ${ }^{46,69}$ To this regard, it is particularly important to know the spheres porous volume, and understand the accessibility of 
water and the pore filling, as well as the occurrence of adsorption and capillary condensation in the voids between the spheres. Indeed, the correct evaluation of these aspects is subject of active investigation, ${ }^{65,68}$ which largely depends on accurate structural information about Stöber spheres. Unfortunately, the abovementioned contradictions existing in the literature can lead to erroneous interpretations.

On account of these considerations, it is still necessary a simple methodology to allow straightforward micropore evaluation (instead of indirect pore volume estimation through measurement of densities or specific surface areas that, in addition, frequently involves expensive facilities like SAXS or NMR). Furthermore, a better knowledge of molecular accessibility to Stöber micropores is required, including water. We directly measure the micropore volume of three different Stöber spheres ( 300-nm size) by $\mathrm{CO}_{2}$ adsorption isotherms at $273 \mathrm{~K}$ and estimate the pore characteristics. By comparison, we explicitly demonstrate that standard $\mathrm{N}_{2}$ isotherms at $77 \mathrm{~K}$ cannot detect any microporosity in these spheres. We further measure water isotherms to prove that a large amount of water can fill the microporous volume, being its humidity-dependent accessibility discussed. Combined features of these adsorption measurements give relevant insights into the different adsorbate accessibilities and pore characteristics of the Stöber spheres.

\section{RESULTS}

\subsection{Nitrogen adsorption isotherms}

As the conventional methodology for micro- and mesoporosity evaluation, we first perform $\mathrm{N}_{2}$ adsorption measurements at $77 \mathrm{~K}$. Figure 1 shows the $\mathrm{N}_{2}$ adsorption/desorption measurements for the three SFB spheres evaluated. As it can be appreciated, all samples exhibit 
very similar isotherms, whose shape corresponds to the type II (IUPAC recommendation), characteristic of multilayer adsorption in non-porous materials. In fact, the amount adsorbed at low relative pressures $\left(\mathrm{p} / \mathrm{p}_{0}<0.1\right)$, corresponding to the adsorption in micropores, is very low $\left(<5 \mathrm{~cm}^{3} \mathrm{STP} / \mathrm{g}\right)$, demonstrating the virtual absence of microporosity accessible to nitrogen at 77 $\mathrm{K}$ in all spheres evaluated. After a slow ramp all along the mid relative pressures, nitrogen adsorption exhibited a large increase above $\mathrm{p} / \mathrm{p}_{0}=0.8$, attributed to the condensation in the voids, that is, in the interparticle space between the spheres. This capillary condensation is larger for SFB-260 and SFB-245, in accordance with their smaller particle size.

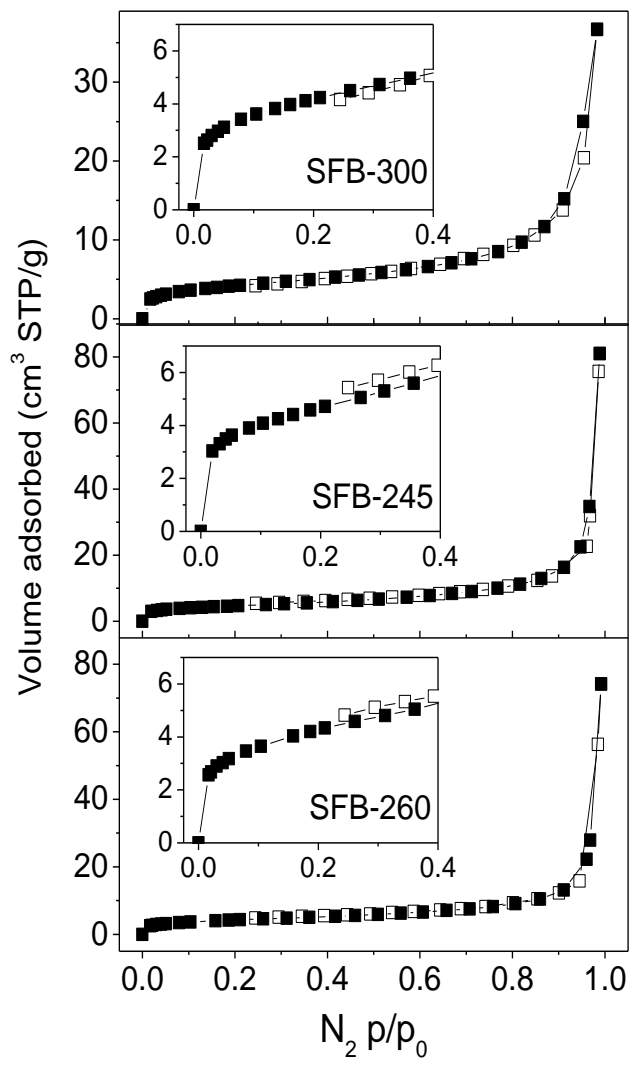

Figure $1 \mathrm{~N}_{2}$ adsorption (filled symbols) and desorption (empty symbols) isotherms for SFB300, SFB-245 and SFB-260 spheres samples at 77 K. Insets: zoomed-in low-pressure regions. 
The resulting textural characteristics of the samples have been calculated using the BET equation to estimate the apparent surface area $\left(S_{B E T}\right)$ and the Dubinin-Radushkevich (DR) equation to calculate the micropore volume $\left(V_{0}\right){ }^{70}$ Table 1 contains a summary of the calculated parameters. The obtained $S_{B E T}$, only slightly larger than the external (geometrical) spheres surface $\left(S_{\text {ext }}\right)$, and the very small $V_{0}$ indicate both low surface roughness and, apparently, scarce microporosity. Similar results have frequently been obtained from $\mathrm{N}_{2}$ adsorption in Stöber spheres, although the possible inaccessibility of nitrogen at cryogenic temperatures to the inner porosity has unfortunately been often ignored, as mentioned above. Interestingly, we found a small delay between adsorption and desorption branches at low relative pressure for samples SFB-245 and SFB-260 (insets in Figure 1). The presence of a certain hysteresis at low pressures reflects the presence of a complex porous structure with associated kinetic restrictions in the adsorption branch. ${ }^{71}$ Similarly delayed desorption has also been observed in other $\mathrm{N}_{2}$ studies on SFB spheres. ${ }^{40,48,58}$ 
Table 1. Textural parameters obtained from the $\mathrm{N}_{2}, \mathrm{CO}_{2}$ and $\mathrm{H}_{2} \mathrm{O}$ adsorption isotherms.

\begin{tabular}{|c|c|c|c|c|c|c|c|c|c|c|}
\hline \multirow[b]{2}{*}{ sample } & \multirow[b]{2}{*}{$\begin{array}{l}S_{\text {ext }}^{a} \\
\left(\mathrm{~m}^{2} / \mathrm{g}\right)\end{array}$} & \multicolumn{3}{|c|}{$\mathrm{N}_{2}$ adsorption } & \multicolumn{3}{|c|}{$\mathrm{CO}_{2}$ adsorption } & \multicolumn{3}{|c|}{$\mathrm{H}_{2} \mathrm{O}$ adsorption } \\
\hline & & $\begin{array}{l}S_{B E T}^{\mathrm{b}} \\
\left(\mathrm{m}^{2} / \mathrm{g}\right)\end{array}$ & $\begin{array}{c}V_{0}^{b} \\
\left(\mathrm{~cm}^{3} / \mathrm{g}\right)\end{array}$ & $\begin{array}{c}V_{t}{ }^{c} \\
\left(\mathrm{~cm}^{3} / \mathrm{g}\right)\end{array}$ & $\begin{array}{l}S_{N L D F T}{ }^{d} \\
\left(\mathrm{~m}^{2} / \mathrm{g}\right)\end{array}$ & $\begin{array}{c}V_{n}{ }^{\mathrm{e}} \\
\left(\mathrm{cm}^{3} / \mathrm{g}\right)\end{array}$ & $\begin{array}{c}\bigvee_{\text {ads }}{ }^{f} \\
\left(\mathrm{~cm}^{3} \text { STP }^{\prime} \mathrm{g}\right)\end{array}$ & $\begin{array}{l}S_{B E T}^{\mathrm{b}} \\
\left(\mathrm{m}^{2} / \mathrm{g}\right)\end{array}$ & $\begin{array}{l}V_{\mathrm{H}_{2} \mathrm{O}} \mathrm{b} \\
\left(\mathrm{cm}^{3} / \mathrm{g}\right)\end{array}$ & $\begin{array}{c}V_{t}{ }^{g} \\
\left(\mathrm{~cm}^{3} / \mathrm{g}\right)\end{array}$ \\
\hline SFB-245 & 13.4 & 17 & 0.0073 & 0.13 & 309 & $0.111(0.110)$ & 31.0 & 210 & 0.089 & 0.122 \\
\hline SFB-260 & 12.6 & 15 & 0.0064 & 0.11 & 262 & $0.090(0.079)$ & 24.2 & 185 & 0.075 & 0.156 \\
\hline SFB-300 & 10.8 & 15 & 0.0065 & 0.06 & 245 & $0.084(0.071)$ & 23.3 & 150 & 0.055 & 0.076 \\
\hline
\end{tabular}

${ }^{a} S_{\text {ext }}=6 / \rho D$, where $\rho$ and $D$ are the bulk density and diameter of the spheres $\left(\rho \approx 1.83 \mathrm{~g} / \mathrm{cm}^{3}\right.$ was taken, as obtained by considering an empty volume of $0.1 \mathrm{~cm}^{3} / \mathrm{g}$ inside the sphere with skeletal (amorphous silica) density of $2.24 \mathrm{~g} / \mathrm{cm}^{3}$ ). ${ }^{\mathrm{b}}$ Apparent surface area calculated from BET and micropore volume calculated after application of the Dubinin-Radushkevich (DR) equation ${ }^{\mathrm{c}}$ Total adsorbed volume measured at $\mathrm{p} / \mathrm{p}_{0}=0.99{ }^{\mathrm{d}}$ Micropore apparent surface area determined after application of the NLDFT model ${ }^{\mathrm{e}}$ Narrow micropore volume calculated from DR equation from $273 \mathrm{~K}$ data (in parentheses, from $298 \mathrm{~K}$ data). ${ }^{\mathrm{f}}$ Total adsorbed volume (assuming ideal gas) measured at 1 bar and $273 \mathrm{~K} .{ }^{\mathrm{g}}$ Total adsorbed volume at $\mathrm{p} / \mathrm{p}_{0}=0.96$. (Note that all volumes calculated from DR equation are expressed considering the probe as a liquid; only $\mathrm{V}_{\text {ads }}$, directly calculated from the $\mathrm{CO}_{2}$ isotherms, is expressed as ideal gas (STP).)

\section{2. $\mathrm{CO}_{2}$ adsorption isotherms}

Previous studies described in the literature ${ }^{72}$ have shown that $\mathrm{CO}_{2}$ adsorption at $273 \mathrm{~K}$ is an excellent probe molecule to complement the nitrogen adsorption results. While standard $\mathrm{N}_{2}$ adsorption provides information about the micro- and mesoporosity of the evaluated sample, it is widely accepted that $\mathrm{CO}_{2}$ adsorption up to atmospheric pressure tests only the narrow porosity (pores below $~ 0.7 \mathrm{~nm}){ }^{72,73}$ Although commonly been employed for carbon materials, $\mathrm{CO}_{2}$ adsorption has barely been applied in the evaluation of silicas due to the presence of specific interactions between the silanol groups and the quadrupole moment of $\mathrm{CO}_{2}$ that can alter (shift to lower pressures) the filling of the narrow micropores and make uncertain the cross-sectional area of the $\mathrm{CO}_{2}$ molecule. However, considering the high specificity of $\mathrm{CO}_{2}$ for 
narrow pores, along with its smaller kinetic diameter $\left(0.33 \mathrm{~nm}\right.$ compared to $0.36 \mathrm{~nm}$ of $\left.\mathrm{N}_{2}\right)$ and the higher adsorption temperature of the measurement $\left(273 \mathrm{~K}\right.$ vs. $77 \mathrm{~K}$ ), $\mathrm{CO}_{2}$ was chosen as probe molecule to evaluate the Stöber spheres and identify potential kinetic restrictions to very narrow (or hardly accessible) micropores.

$\mathrm{CO}_{2}$ isotherms up to atmospheric pressure showed perfect match between adsorption and desorption branches for the three samples evaluated (Figure 2). As observed at $273 \mathrm{~K}$, all samples exhibited a considerable adsorption capacity, with adsorbed volumes of $23-31 \mathrm{~cm}^{3}$ $\mathrm{STP} / \mathrm{g}$ at atmospheric pressure (Table 1). Such significant values unambiguously show that the spheres are indeed substantially microporous, contrasting to the small nitrogen volume adsorbed $\left(<5 \mathrm{~cm}^{3} \mathrm{STP} / \mathrm{g}\right)$. In the same way as before, $\mathrm{CO}_{2}$ adsorption data were evaluated using the DR equation to determine the volume of narrow micropores $\left(V_{n}\right)$ : ca. $0.08-0.1 \mathrm{~cm}^{3} / \mathrm{g}$ was obtained for all samples, being much larger than the total micropore volume $V_{0}$ deduced from the $\mathrm{N}_{2}$ adsorption data (Table 1). Figure 3a shows the high linearity of the DR plot in a representative sample (SFB-245). 


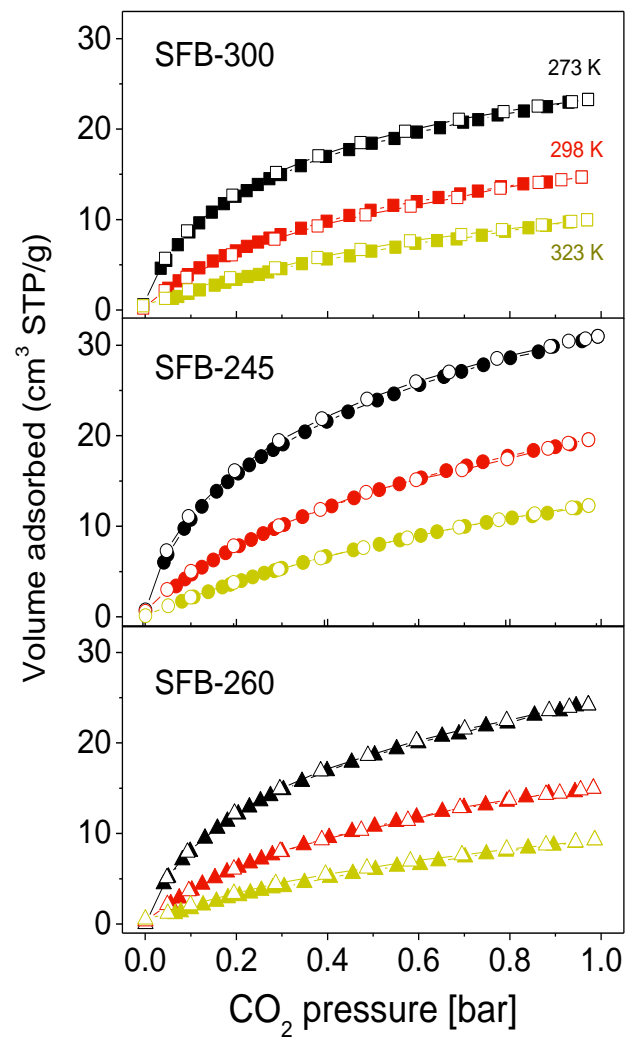

Figure $2 \mathrm{CO}_{2}$ adsorption (filled symbols) and desorption (empty symbols) isotherms for SFB300, SFB-245 and SFB-260 spheres samples at $273 \mathrm{~K}, 298 \mathrm{~K}$ and $323 \mathrm{~K}$. 

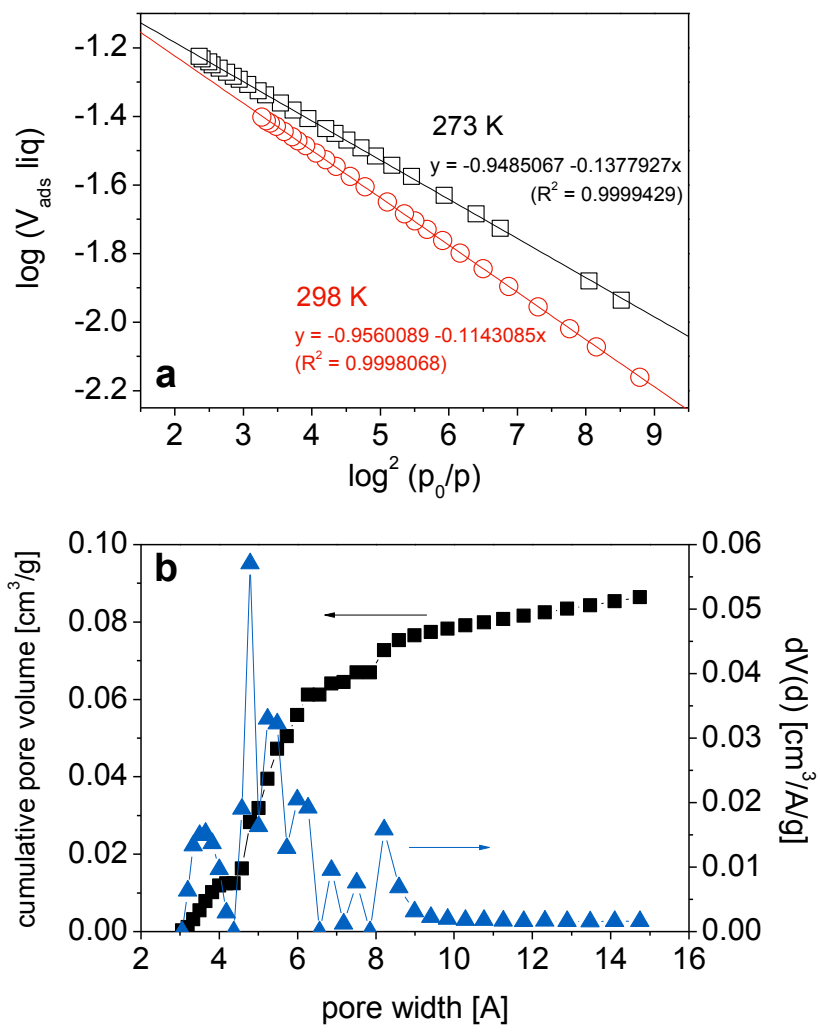

Figure 3.Analysis of $\mathrm{CO}_{2}$ adsorption data. (a) DR plot for 273 and $298 \mathrm{~K}$; fitting parameters of the corresponding linear regressions are shown. b) PSD and cumulative pore volume for $273 \mathrm{~K}$ obtained by NLDFT model (assuming carbon as adsorbent). Data correspond to the sample SFB-245.

In order to analyze if $\mathrm{CO}_{2}$ molecules underwent some kinetic-limited adsorption, isotherms were also performed at $298 \mathrm{~K}$ and $323 \mathrm{~K}$. As observed in Figure 2, all isotherms followed the expected thermodynamic tendency over the whole pressure range: the higher the adsorption temperature, the less the amount adsorbed. Note that, in the case of significant kinetic restrictions for $\mathrm{CO}_{2}$ to access the porosity, the opposite trend would have been observed: at higher temperature, the faster kinetics of the adsorptive molecules would have minimized the restricted accessibility and led to increased adsorption. ${ }^{72}$ DR equation was also applied to the 
$298 \mathrm{~K}$ data assuming the density of liquid $\mathrm{CO}_{2}$. (DR application was precluded at $323 \mathrm{~K}$ as $\mathrm{CO}_{2}$ is in supercritical conditions). As shown in Figure 3a, the linearity of the DR plot is maintained at $298 \mathrm{~K}$ and the intersect of the fitting straight line, which yields $V_{n}$, is rather coincident to that of $273 \mathrm{~K}$, thus excluding any diffusional limitation. On account of these results, we can consider $\mathrm{CO}_{2}$ molecules having full accessibility to the narrow Stöber microporosity under standard experimental conditions, validating its adequacy for micropore evaluation of Stöber spheres. (Similar behavior was also obtained for the other two samples; note that some differences in $V_{n}$ were observed -see Table 1-, which may arise from the interaction with the silica surface, leading to some tilting of the adsorbed $\mathrm{CO}_{2}$ molecules and alteration of the assumed density).

An open question at this point concerns the size of Stöber porosity. Standardly, pore size distributions (PSD) are calculated through the application of density functional theory (DFT) models to $\mathrm{N}_{2}$ adsorption data, ${ }^{74}$ but the barely detected microporosity ruled out this option. In the uncommon case of $\mathrm{CO}_{2}$ adsorption measurements on silica, DFT is not applied due to the presence of specific interactions of $\mathrm{CO}_{2}$ with the silica surface (in fact, DFT models for $\mathrm{CO}_{2}$ adsorption in silica are not provided by commercial software). Being aware of this, we applied the available DFT model for carbon materials to our $\mathrm{CO}_{2}$ adsorption data. Although this assumption is obviously not fully correct, it complements the general picture about the porous structure in these systems. To this end, Figure $3 b$ shows the resulting evaluation of the cumulative pore volume and the PSD for a representative sample (SFB-245). According to this approximation, the PSD shows an extensively developed narrow microporosity in the Stöber spheres, with main contributions in the size range of $0.3-0.6 \mathrm{~nm}$. The total surface area estimated from these calculations is ca. $300 \mathrm{~m}^{2} / \mathrm{g}$ (Table 1). 


\subsection{Water adsorption isotherms}

The small kinetic diameter of $\mathrm{H}_{2} \mathrm{O}(0.265 \mathrm{~nm})$ constitutes a priori an advantage for the characterization of microporous solids with narrow constrictions. However, it is important to highlight that water adsorption mechanism in nanoporous solids is quite complex due to the high sensitivity of water molecules to the surface chemistry, by contrast with the cases of $\mathrm{N}_{2}$ and $\mathrm{CO}_{2}$. For instance, in the case of hydrophobic carbon materials, water adsorption proceeds through cluster formation (up to several water molecules), while the adsorption on silicas is more uniform and defined by the hydroxyl groups (silanols) in the surface. ${ }^{75,76}$ Thus, water isotherms not only characterize the presence of porosity but also fundamental aspects of the sorption behavior of water molecules, like the surface affinity or the pore accessibility.

Figure 4 shows the water adsorption isotherms at $298 \mathrm{~K}$ for our three Stöber samples, evaluated up to two different relative pressures, 0.85 and 0.96 . In all cases, the amount of water adsorbed at low relative pressures $\left(\mathrm{p} / \mathrm{p}_{0}<0.2\right)$ is very significant $\left(>50 \mathrm{~cm}^{3} \mathrm{STP} / \mathrm{g}\right)$ and the isotherm shape corresponded to a type II, according to the IUPAC classification. This behavior is typically observed in hydrophilic materials and clearly reflects the presence of specific interactions of water with the silica surface, even at low relative pressure. At higher relative pressures, the amount adsorbed increased smoothly until $\mathrm{p} / \mathrm{p}_{0} \sim 0.8$, where capillary condensation in the voids between particles begins to take place (a change in the slope of the adsorption branch is observable). A BET surface area of $\sim 150-200 \mathrm{~m}^{2} / \mathrm{g}$ from water adsorption was estimated for the three spheres (Table 1), in fair agreement with the apparent surface areas calculated from the $\mathrm{CO}_{2}$ adsorption data, although being systematically smaller. The micropore volume for water $\left(V_{\mathrm{H}_{2} \mathrm{O}}\right)$ was also calculated using the DR equation applied to the water adsorption values (see Table 1). $V_{\mathrm{H}_{2} \mathrm{O}}$ follows the same tendency in the three samples than $V_{n}$ 
calculated from $\mathrm{CO}_{2}$, being again somewhat smaller (ca. 20-30\% smaller). Assuming the validity of the DR equation for water adsorption in silicas, this observation points to some limited accessibility of water to the microporosity in SFB spheres.

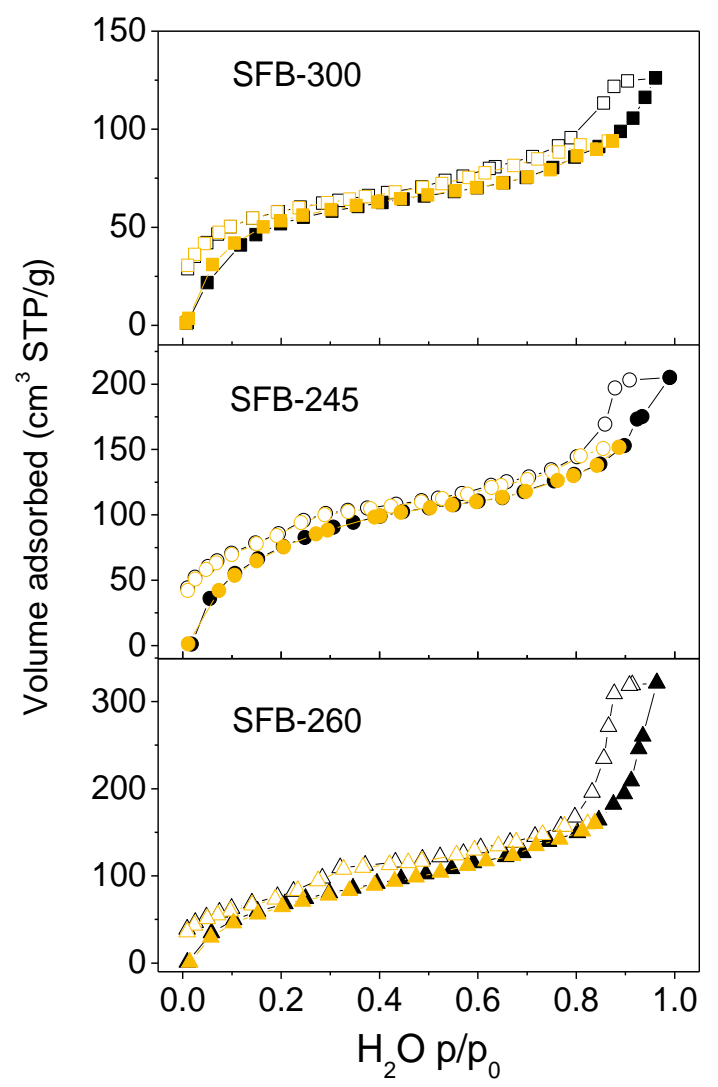

Figure $4 \mathrm{H}_{2} \mathrm{O}$ adsorption (filled symbols) and desorption (empty symbols) isotherms for SFB300, SFB-245 and SFB-260 spheres samples at $298 \mathrm{~K}$. Isotherms were measured up to $\sim 0.96$ or 0.85 relative pressure (black and orange symbols).

For $\mathrm{p} / \mathrm{p}_{0}>0.9$, capillary condensation occurred in the voids, which was associated with a type H4 hysteresis loop (Figure 4). This loop disappeared when the adsorption branch stopped at $\mathrm{p} / \mathrm{p}_{0}<0.9$, thus precluding the voids filling, and the rest of the isotherm was perfectly reproducible. In both cases, that is, independently of the onset of capillary condensation, the 
desorption branch exhibited a lasting delay compared to the adsorption branch. This delay even increased at very low relative pressures, a phenomenon usually known as low-pressure hysteresis. Last but not least, the presence of an additional, small hysteresis loop was found at mid relative pressures $\left(0.2<\mathrm{p} / \mathrm{p}_{0}<0.5\right)$, preferentially in the sample SFB-260, indicating capillary condensation in some narrow mesopores. Although the amount of these mesopores (or large micropores) must be quite limited, it is remarkable that water adsorption could detect them while $\mathrm{N}_{2}$ adsorption could not.

\section{DISCUSSION}

\subsection{Porosity quantification}

$\mathrm{CO}_{2}$ adsorption isotherms have shown, directly and unambiguously, the existence of large microporous volume in all Stöber spheres measured. Straightforward DR calculation yielded a narrow micropore volume $V_{n} \sim 0.08-0.11 \mathrm{~cm}^{3} / \mathrm{g}$, which corresponds to ca. $15-20 \%$ of the Stöber sphere volume and $\rho \approx 1.8-1.9 \mathrm{~g} / \mathrm{cm}^{3}$ as density of the empty (evacuated) sphere. A similar but lower micropore volume $V_{\mathrm{H}_{2} \mathrm{O}} \sim 0.06-0.09 \mathrm{~cm}^{3} / \mathrm{g}$ was obtained from water isotherms, using the DR equation as well (Table 1 It is important to note that, assuming that both $\mathrm{CO}_{2}$ and $\mathrm{H}_{2} \mathrm{O}$ are filling the cavities with the condensed adsorptive in the normal liquid density (Gurvich rule ${ }^{36}$ ), $V_{n}$ and $V_{H_{2} O}$ (in liquid units) should be coincident, provided that both probe molecules fill the same porosity. The obtained volumes are in fair accordance with some of the very few direct measurements of micropore volume previously reported in SFB spheres, in the range of $0.05-0.13 \mathrm{~cm}^{3} / \mathrm{g} .{ }^{31,40,41,44}$ Other authors measured much larger accessible volumes, e.g. $0.23 \mathrm{~cm}^{3} / \mathrm{g}$ from $\mathrm{CO}_{2}$ isotherms ${ }^{54}$ and $0.32 \mathrm{~cm}^{3} / \mathrm{g}$ from spin-echo small-angle neutron scattering. ${ }^{77}$ Such large micropore volumes seems to be overestimated, since they 
would correspond to spheres with an empty volume of $>40 \%$ (mass density $<1.3 \mathrm{~g} / \mathrm{cm}^{3}$ ), a fact hardly reconcilable with the densities usually measured $\left(>1.8 \mathrm{~g} / \mathrm{cm}^{3}\right)$. Also, by considering the porosity effect on the mechanical robustness, ${ }^{78}$ the high Young modulus of Stöber spheres (about half of the silica bulk value), ${ }^{50}$ agrees with the porosity we estimate, while a drastic decrease in a factor of ten would be expected for $40 \%$ porosity. Other volume estimates are indirectly deduced from density measurements, mainly, and span over a larger range (e.g. $\left.11-15 \%,{ }^{27} 15-24 \%,{ }^{50} \sim 12 \%,{ }^{49}\right)$, although agreeing reasonably with our result.

Our $\mathrm{CO}_{2}$ adsorption measurements also allowed direct calculation of the apparent surface area of $\sim 250-300 \mathrm{~m}^{2} / \mathrm{g}$ using DFT. Although we applied a model for carbon adsorbents (instead of silica, which is not available), this area is roughly comparable to the BET surface area of $\sim 150-200 \mathrm{~m}^{2} / \mathrm{g}$ obtained from water adsorption data (Table 1). Such acceptable agreement validates the approximation undertaken. The difference between both values could be ascribed to an overestimate of the actual $\mathrm{CO}_{2}$ cross-sectional area in silica, if the $\mathrm{CO}_{2}$ molecules undergo some orientation due to interaction between its quadrupole moment and the polar silanol groups. However, the water adsorption could also underestimate the actual surface area if the access of water molecules to the inner volume is somewhat limited, in particular at very low pressures. This option seems probable in accord with the fact that $V_{\mathrm{H}_{2} \mathrm{O}}<V_{n}$, (see below). A comparison with literature values is difficult, since a huge range of apparent surface areas (100 to $1300 \mathrm{~m}^{2} / \mathrm{g}$ ) has been obtained by a variety of methods ${ }^{15,25,34,35,39-44,46,48,54,60}$ (not including numerous reports of vanishing surface area from $\mathrm{N}_{2}$ isotherms).

Our three Stöber samples exhibited a similar degree of microporosity, although with consistent differences between them. SFB-300 presented somewhat smaller both micropore volumes and apparent surface areas than SFB-260, and this in turn showed slightly smaller 
values than SFB-245 (Table 1), indicating distinct development of microporosity. The micropore size range of 0.3-0.6 nm obtained from $\mathrm{CO}_{2}$ adsorption was similar in all cases; note that, although a DFT model for carbon and not for silica was applied, as discussed above, this PSD is in fair accordance with other authors indicating a cut-off size in Stöber spheres of 0.3 $\mathrm{nm}^{14,15,23}$ and a pore size span of $0.3-0.5 \mathrm{~nm} .{ }^{64}$ Taking into account that $V_{n}$ (from $\mathrm{CO}_{2}$ data) is exclusively sensitive to narrow microporosity, the lower value achieved for $V_{\mathrm{H}_{2} \mathrm{O}}$ indicates limited access for water to these narrow constrictions. Contrasting the values (Table 1; see also Figure 5 for graphical comparison), the smallest difference is found for SFB-260, suggesting a larger fraction of wider micropores; according to this argument, SFB-300, as it shows the biggest discrepancy between $V_{n}$ and $V_{\mathrm{H}_{2} \mathrm{O}}$, would have the largest proportion of narrow pores. This trend is coincident with the observation of mid-pressure hysteresis in the water isotherms (Figure 4), mainly in SFB-260 but also in SFB-245, indicating certain small mesoporosity, while no hysteresis was discernible in SFB-300. Given the early occurrence (low $\mathrm{p} / \mathrm{p}_{0}$ ) of the hysteresis, small mesopores of 2-4 nm can be suggested. 


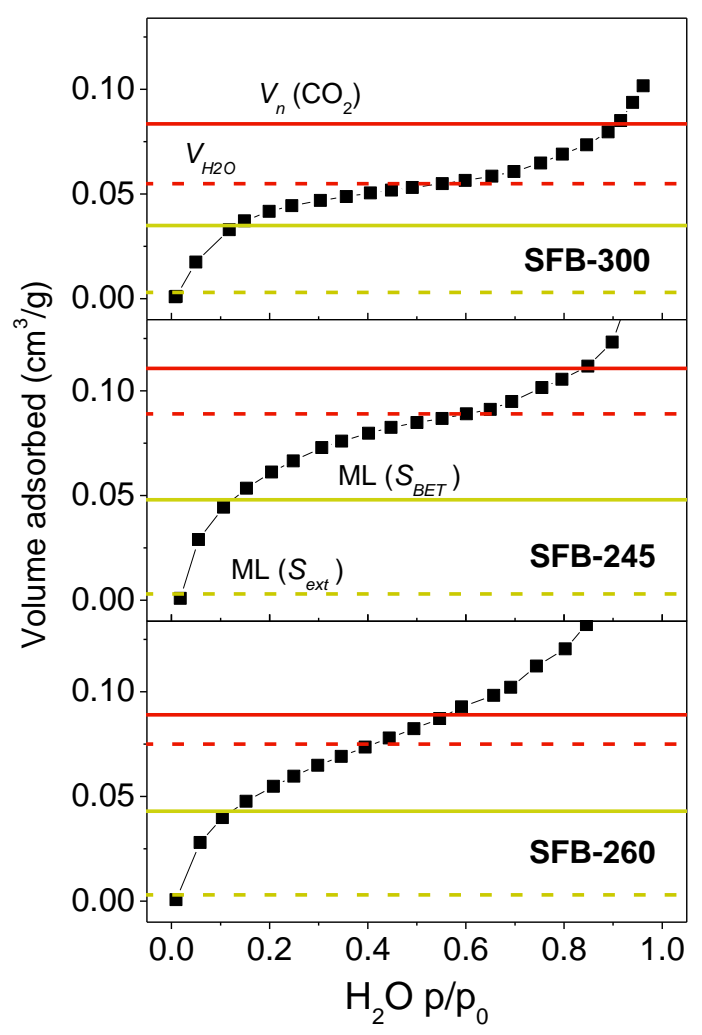

Figure 5. $\mathrm{H}_{2} \mathrm{O}$ adsorption isotherms at $298 \mathrm{~K}$ (symbols) for SFB-300, SFB-245 and SFB-260 spheres samples. For sake of comparison, the corresponding micropore volumes $V_{n}$, obtained from $\mathrm{CO}_{2}$ adsorption data, and $V_{\mathrm{H}_{2} \mathrm{O}}$ (solid and dashed red lines), and the water monolayer volumes on the BET and external surface areas, $M L\left(S_{B E T}\right)$ and $M L\left(S_{\text {ext }}\right)$, respectively (solid and dashed green lines) are also represented. The monolayer volumes were calculated assuming a covering of $0.28 \mathrm{mg} / \mathrm{m}^{2} .59$

It is known that several factors, such as synthesis parameters, sphere size and postfabrication aging, may influence the internal structure of Stöber spheres. ${ }^{27,32,35,43,44}$ In this study, spheres with very similar synthesis and size were employed, in order to discard such influences; indeed, no correlation between the type of porosity and our spheres size was found. By contrast, 
as a distinguishing aspect, samples with different aging were chosen. In fact, our samples have different ages, being SFB-260 the eldest one (about ten years) and SFB-300 the newest one (one year). According to this hypothesis, aging would favor the development of larger microporosity or even the creation of some mesoporosity. A plausible mechanism would be pore coarsening, through which dissolution and re-deposition of silica, preferentially at convex surfaces (Ostwald ripening), would lead to gradual increase of the average pore size. ${ }^{79}$ Indeed, pore coarsening during aging is known in microporous systems such as gels ${ }^{35,80}$ and membranes ${ }^{81}$. Future studies should confirm this proposition.

Finally, since nitrogen isotherms at $77 \mathrm{~K}$ virtually detect only open porosity in Stöber spheres (see next Section), the corresponding $S_{B E T}$ rather reflects the SFB surface roughness. Thus, the fact that $S_{B E T}\left(\mathrm{~N}_{2}\right)$ in our samples were only slightly larger than the corresponding external surface areas (Table 1) denotes relatively smooth sphere surfaces.

\subsection{Molecular accessibility}

Given the evidence of significant microporosity found in our Stöber spheres, the type II $\mathrm{N}_{2}$ isotherms measured in the same samples (Figure 1) unambiguously demonstrate that nitrogen at $77 \mathrm{~K}$ has strongly restricted access to the inner volume. Both micropore volume and apparent surface area obtained from $\mathrm{N}_{2}$ adsorption data underestimated those measured by $\mathrm{CO}_{2}$ or $\mathrm{H}_{2} \mathrm{O}$ isotherms in about 15-20 times (Table 1). On the contrary, $\mathrm{CO}_{2}$ molecules at $273 \mathrm{~K}$ exhibited no access restrictions to Stöber microporosity, as demonstrated here for the first time. Such conclusion was drawn from adsorption experiments at higher temperature, along with the perfect match between adsorption and desorption branches in all cases and the linearity of DR plots. 
The allowed entrance of $\mathrm{CO}_{2}$, in turn, indicates that the non-access of the similarly large $\mathrm{N}_{2}$ molecules must be attributed to serious kinetic restrictions at $77 \mathrm{~K}$, as pointed out previously. ${ }^{23,32,35,37-40}$ Indeed, only the lower size region of the estimated PSD (0.3-0.6 nm) should hinder the entrance to nitrogen, which is usually capable to probe narrow pore sizes down to $0.35-0.4 \mathrm{~nm}$, even at $77 \mathrm{~K}$. This argument rather points to a peculiar morphology of the Stöber porous structure as main responsible for the difficult access, probably involving strongly constricted entrances of micropores, high tortuosity and, probably, compacter outer sphere region. ${ }^{15,32}$ Then, such a particular structure, rather than the pore size, would avoid molecules without enough kinetic energy to probe the inner volume. (Note that spheres posttreatment can largely relieve such pore blocking to $\mathrm{N}_{2}$ at $77 \mathrm{~K},{ }^{40,44}$ although it was possibly accompanied by some pore enlargement, since a resulting pore size of $0.8-1.1 \mathrm{~nm}$ was reported there). Remarkably, we further proved that $\mathrm{N}_{2}$ at $77 \mathrm{~K}$ cannot even properly detect small mesoporosity, which was however distinguished by water isotherms. The observation of some hysteresis in the $\mathrm{N}_{2}$ isotherms of samples SFB-260 and SFB-245 (Figure 1, insets) reflects the complexity of the porous Stöber structure, as it evidences the extremely difficult pore access of nitrogen even to those samples exhibiting wider porosity (as discussed in the previous Section). In the case of SFB-300, with no mesoporosity, the $\mathrm{N}_{2}$ adsorption consistently exhibited no hysteresis (Figure 1), indicating again that $\mathrm{N}_{2}$ molecules did not probe the Stöber microporosity. These facts evidence that $\mathrm{N}_{2}$ adsorption isotherms are an unsuitable means for pore evaluation in Stöber spheres and should not be considered as proof of nonporosity in such system (and potentially in others with difficult pore access ${ }^{82}$ ).

Water adsorption isotherms demonstrated that the Stöber micropores were also accessible to water vapor molecules at room temperature. Such accessibility is relevant as it implies that 
the inner Stöber volume can be filled with water e.g. taken from the surrounding moisture under normal ambient conditions. However, this has barely been investigated and water adsorption isotherms in Stöber spheres has rarely been reported. ${ }^{15,34,59,75}$ As discussed above, both micropore volume and area calculated in our samples from the water adsorption data were in reasonable agreement with those obtained from $\mathrm{CO}_{2}$ data, also serving for evaluation of SFB microporosity. As an advantage, water isotherms additionally allowed revealing mesoporosity, which is undetectable for $\mathrm{CO}_{2}$. Nevertheless, the delay of the desorption branch observed in all samples (Figure 4) denotes some restriction in the adsorption process. This would be consistent with e.g. density measurements, usually yielding lower values for $\mathrm{H}_{2} \mathrm{O}$ than for He pycnometry, which had already suggested being due to limited access of water to the inner Stöber volume. $^{27,28,}$ Thus, a possibility is the existence of narrow pores with singular constrictions, which would be accessible only at high relative pressures: during the desorption branch, these pores would be difficult to evacuate, causing the delay and the final entrapment of water molecules at $\mathrm{p} / \mathrm{p}_{0}<0.1$ (low-pressure hysteresis). However, an active role of the surface chemistry cannot be ruled out. ${ }^{34,75}$ For instance, the development of stronger bonds between water molecules and silanols along the adsorption branch would require some extra driving force (lower relative pressure) during desorption, leading to the delay. Further investigation is required to discern the mechanisms involved.

\subsection{Water uptake and location}

As stated above, it is important to know not only the ability of the Stöber silica to uptake water, from e.g. humid air, but also where this water is placed, whether inside the spheres porosity or outside (in the interparticle voids). To get a deeper insight, we re-plot the water isotherms (adsorption branches only) in units of water volume as a liquid (Figure 5, symbols) 
and compare with the corresponding micropore volumes deduced along the article, i.e. $V_{n}$ and $V_{\mathrm{H}_{2} \mathrm{O}}$ (Figure 5, red horizontal lines).

The narrow micropore volume $V_{n}$, obtained from $\mathrm{CO}_{2}$ adsorption, exceeds the water isotherm during most of the range of relative pressures. Thus, the water uptake in SFB-300 equals $V_{n}$ only at $\mathrm{p} / \mathrm{p}_{0} \sim 0.9$, which indicates that, up to this relative humidity, the water adsorbed can be allocated in the micropores inside the spheres. The water isotherm surpasses $V_{n}$ only at higher pressures, as the capillary condensation sets in and the voids, in the inter-sphere space, had started to be filled. By contrast, the calculated $V_{\mathrm{H}_{2} \mathrm{O}}$ cut the water isotherms of SFB300 at $\mathrm{p} / \mathrm{p}_{0} \sim 0.5$. This point is coincident with a change in the isotherm slope, a fact that is compatible with the saturation of the micropore volume accessible for water and the beginning of voids through multilayer adsorption on the spheres external surface. The sample SFB-260 exhibits a certain deviation from this picture, in which the water adsorption branch reaches the micropore volume $V_{\mathrm{H}_{2} \mathrm{O}}$ at a lower pressure $\left(\mathrm{p} / \mathrm{p}_{0} \sim 0.4\right)$ and keeps growing faster than the other two samples (Figure 5). We attribute this fact to the higher proportion of accessible microporosity (as described above) and the appreciable mesoporosity detected (Figure 4), which leads to extra water uptake at mid pressures from capillary condensation in these small mesopores (or large micropores). As this volume is not accounted by $V_{n}$, this value is reached by the water isotherm sooner, at $\mathrm{p} / \mathrm{p}_{0} \sim 0.55$, in spite of not having the largest micropore volume $V_{\mathrm{H}_{2} \mathrm{O}}$ (Table 1). SFB-245, which exhibited a slight mesoporosity (Figure 4), presents an intermediate behavior: its adsorption branch grows with a slope between those of SFB-260 and the non-mesoporous SFB-300, and cuts $V_{n}$ at $\mathrm{p} / \mathrm{p}_{0} \sim 0.8$.

This analysis provides direct evidence of the location of the adsorbed water as function of the relative humidity. It is shown that a significant amount of water is taken from surrounding 
humidity at normal ambient conditions $\left(\mathrm{p} / \mathrm{p}_{0}=0.3-0.5\right.$ and $\left.25^{\circ} \mathrm{C}\right)$. This agrees with the water contained in aggregates of Stöber spheres at standard laboratory conditions, which has often been measured by TGA, typically corresponding to $5-8$ wt. $\%,^{23,32,40,41,45,46,52,54,57,69,76}$ or, equivalently, $0.05-0.08 \mathrm{~cm}^{3} / \mathrm{g}$. However, any discussion about where this water is placed is practically absent in the literature. Here, as a major conclusion, we demonstrate that the water adsorbed by Stöber spheres at $\mathrm{p} / \mathrm{p}_{0}<0.6$ is predominantly located inside the spheres, filling the significant inner micropore volume. This is consistent with the Polanyi potential theory for open surfaces and the presence of van der Waals interactions between the gas molecules and the host surface, determining the adsorption potential. In narrow cavities with facing surfaces, these interactions overlap and the adsorption potential is larger, defining the sequence of pore filling, which is preferential in the case of smaller pores.

From the BET calculation of the specific (microporous) surface area accessed by the water molecules, the corresponding volume of water covering this surface (building a monolayer, as assumed by the BET theory) is represented in Figure $5\left(\mathrm{ML}\left(S_{B E T}\right)\right.$, solid green lines). Figure 5 shows that these values are clearly below the corresponding micropore volumes $\mathrm{V}_{\mathrm{H}_{2} \mathrm{O}}$, suggesting that the micropores are progressively filled by more than a monolayer. Indeed, $\operatorname{ML}\left(S_{B E T}\right)$ values coincide well with the knees of the isotherms in all three samples (the socalled point B), which mark a slowing down in the isotherm that is compatible with monolayer completion and begin of multilayer formation in the micropore filling mechanism. Notice that, during micropore filling, the concomitant adsorption of a water monolayer on outer sphere surface is probable; however, such a monolayer would amount a volume $\operatorname{ML}\left(S_{\text {ext }}\right)<0.003$ $\mathrm{cm}^{3} / \mathrm{g}$, so it would be hardly distinguishable from the growing micropore filling (Figure 5, dashed green lines). On the other hand, the transition between micropore filling and capillary 
condensation in the voids must surely involve the progressive growth of water multilayers on the outer surface of the spheres. From the water adsorption data, multilayer adsorption probably occurs mostly at $\mathrm{p} / \mathrm{p}_{0}=0.6-0.8$ in our samples.

\section{CONCLUSIONS}

Here we have assessed a significant microporosity in Stöber spheres by simple $\mathrm{CO}_{2}$ adsorption isotherms, allowing direct quantification of the narrow micropore volume $\left(V_{n} \sim 30\right.$ $\mathrm{cm}^{3} \mathrm{STP} / \mathrm{g}$ or $\left.0.1 \mathrm{~cm}^{3} / \mathrm{g}\right)$ and apparent surface area $\left(S_{N L D F T} \sim 300 \mathrm{~m}^{2} / \mathrm{g}\right)$. We demonstrate for the first time that $\mathrm{CO}_{2}$ molecules at $273 \mathrm{~K}$ exhibited no access restrictions to Stöber microporosity. We further proved, by contrast, the non-accessibility of $\mathrm{N}_{2}$ molecules at $77 \mathrm{~K}$ to this microporosity due to drastic kinetic restrictions. The obtained pore sizes suggested that such limitation rather relies on the peculiar pore morphology in the spheres (involving tortuous channels and restrained pore entrances), which is compatible with actual models for Stöber growth considering the progressive aggregation of nanometric granules and final structure densification. $^{22-24}$

At the same time, we also showed the high accessibility of water molecules to the spheres inner porosity, although some access constraints are suggested. As an advantage, water isotherms detected microporosity above $0.7 \mathrm{~nm}$ and even slight, aging-related mesoporosity in our samples, thus complementing the pore evaluation by $\mathrm{CO}_{2}$ adsorption. Furthermore, it was found that the adsorbed water is preferentially located inside the spheres up to $\mathrm{p} / \mathrm{p}_{0}=0.6$, while the voids between spheres are significantly filled only at higher pressures. The availability of the microporous structure of Stöber spheres for water filling (and emptying) under usual humidity conditions has barely been studied, although it will surely affect e.g. their mechanical 
properties, individual $^{50}$ and collectively, ${ }^{83}$ charge state $^{62,63}$ or optical performance of Stöbercomposed colloidal crystals. ${ }^{6}$ Our findings of unambiguous and notable water uptake in the micropores, together with previous evidence of fast dynamics related to water sorption in Stöber spheres, ${ }^{65,84}$ may also raise questions about the ability of water to easily, and rapidly, adsorb and desorb in such strongly confined environment. Work is currently in progress in order to account for kinetics aspects and achieve deeper understanding about water access mechanisms.

We then propose $\mathrm{CO}_{2}$ adsorption isotherms as a simple means for reliable evaluation of Stöber narrow microporosity, which represents a radical advantage over demanding techniques such as SAXS or NMR. Water isotherms are a suitable complement for evaluation of larger microporosity and mesoporosity. Moreover, we emphasize the inadequacy of the conventionally employed $\mathrm{N}_{2}$ isotherms for micropore detection in Stöber spheres, as explicitly demonstrated here, and, possibly, in other microporous systems.

\section{ACKNOWLEDGMENTS}

This work was funded by Spanish MINECO MAT2014-58731-JIN, MAT2015-68075-R, MAT2016-80285-p and SIFE2 projects; Comunidad de Madrid S2013/MIT-2740 and PHAMA_2.0 projects; Generalitat Valenciana PROMETEOII/2014/004 project and EU H2020 MSCA-RISE-2016/NanoMed Project.

\section{METHODS}

Stöber Silica Spheres Three different Stöber silica monodisperse spheres were purchased from the same manufacturer (Microparticles $\mathrm{GmbH}$ ). Scanning electron microscopy (FEI Nova NANOSEM 230) verified their sphericity and apparently smooth surface. Size and dispersion 
were determined to be 300, 245 and $260 \mathrm{~nm}$ and $<3 \%$ polydispersity. Solid spheres packings were obtained by vertical sedimentation and drying under ambient conditions ( $35 \%$ humidity). The samples, accordingly named as SFB-300, SFB-245 and SFB-260 and, have different ages since fabrication (about 1, 3 and 10 years, respectively) and were stored under ambient conditions in closed vessels. Thermogravimetric and infrared measurements ${ }^{46,76}$ indicated that the spheres surface was fully hydroxylated (ca. 5 silanols $/ \mathrm{nm}^{2}$, Ref. 75), as expected. Elemental analysis (Perkins Elmer 2400) showed small amounts of carbon $(<0.4 \%)$ in all samples, indicating low degree of incomplete hydrolysis of ethoxy groups during synthesis. No impurities were found.

Textural Characterization The textural properties of the Stöber spheres were evaluated by $\mathrm{N}_{2}$ adsorption at $77 \mathrm{~K}$ and $\mathrm{CO}_{2}$ adsorption at 273, 298 and $323 \mathrm{~K}$. These measurements were performed in a home-made fully automated manometric equipment designed and constructed by the LMA group, and now commercialized by G2MTech. Gas adsorption measurements were performed under strict equilibrium conditions (equilibrium points: 10; interval time: $120 \mathrm{~s}$; sorption rate limit: 0.001 Torr/min). Before the adsorption measurements the samples were outgassed at $393 \mathrm{~K}$ for $12 \mathrm{~h}$ under UHV conditions. Water adsorption measurements were performed under similar conditions at $298 \mathrm{~K}$ (equilibrium points: 10; interval time: $30 \mathrm{~s}$; sorption rate limit: $0.005 \mathrm{Torr} / \mathrm{min}$ ). These measurements were performed in a home-made fully automated manometric equipment, now commercialized by Quantachrome as VStar. Apparent surface area was estimated from $\mathrm{N}_{2}$ and $\mathrm{H}_{2} \mathrm{O}$ adsorption data after application of the BET equation:

$$
\frac{1}{n\left[\left(\frac{\mathrm{p}_{0}}{\mathrm{p}}\right)-1\right]}=\left(c-\frac{1}{n_{m} \mathrm{c}}\right)\left(\frac{\mathrm{p}}{\mathrm{p}_{0}}\right)+\frac{1}{n_{m} c}
$$


where $n$ is amount adsorbed at each relative pressure, $n_{m}$ is the specific monolayer capacity, and $c$ is the BET constant. The BET equation was applied in the relative pressure range up to 0.15 . A cross-sectional area of $0.162 \mathrm{~nm}^{2}$ and $0.106 \mathrm{~nm}^{2}$ for $\mathrm{N}_{2}$ and $\mathrm{H}_{2} \mathrm{O}$ adsorption on silicas.

The micropore volume for $\mathrm{N}_{2}, \mathrm{CO}_{2}$ and $\mathrm{H}_{2} \mathrm{O}$ was estimated from the Dubinin-Radushkevich (DR) equation:

$$
\log V=\log V_{0}-\mathrm{A} \log ^{2}\left(\frac{\mathrm{p}_{0}}{\mathrm{p}}\right)
$$

where $V$ is volume adsorbed, $V_{0}$ is the micropore volume (referred to as $V_{n}$ and $V_{\mathrm{H}_{2} \mathrm{O}}$ in the specific cases of $\mathrm{CO}_{2}$ and $\mathrm{H}_{2} \mathrm{O}$ for clarity) and $A$ is a constant. The DR plot was linear over the whole pressure range for $\mathrm{CO}_{2}$ (Figure 3a). For $\mathrm{N}_{2}$ and $\mathrm{H}_{2} \mathrm{O}$, however, the DR plot exhibited a typical S-shape; therefore, only the linear region was used to estimate the corresponding micropore volume, this region ranging from $\log ^{2}\left(\mathrm{p}_{0} / \mathrm{p}\right)=2$ to 10 for $\mathrm{N}_{2}$ and from 0.5 to 1.5 for $\mathrm{H}_{2} \mathrm{O}$. The liquid densities used for these calculations are: $\mathrm{N}_{2}\left(0.808 \mathrm{~g} / \mathrm{cm}^{3}\right), \mathrm{CO}_{2}\left(1.023 \mathrm{~g} / \mathrm{cm}^{3}\right.$ at $273 \mathrm{~K}$ and $0.97 \mathrm{~g} / \mathrm{cm}^{3}$ at $\left.298 \mathrm{~K}\right)$, and $\mathrm{H}_{2} \mathrm{O}\left(0.997 \mathrm{~g} / \mathrm{cm}^{3}\right)$. 


\section{TABLE OF CONTENTS (TOC)}

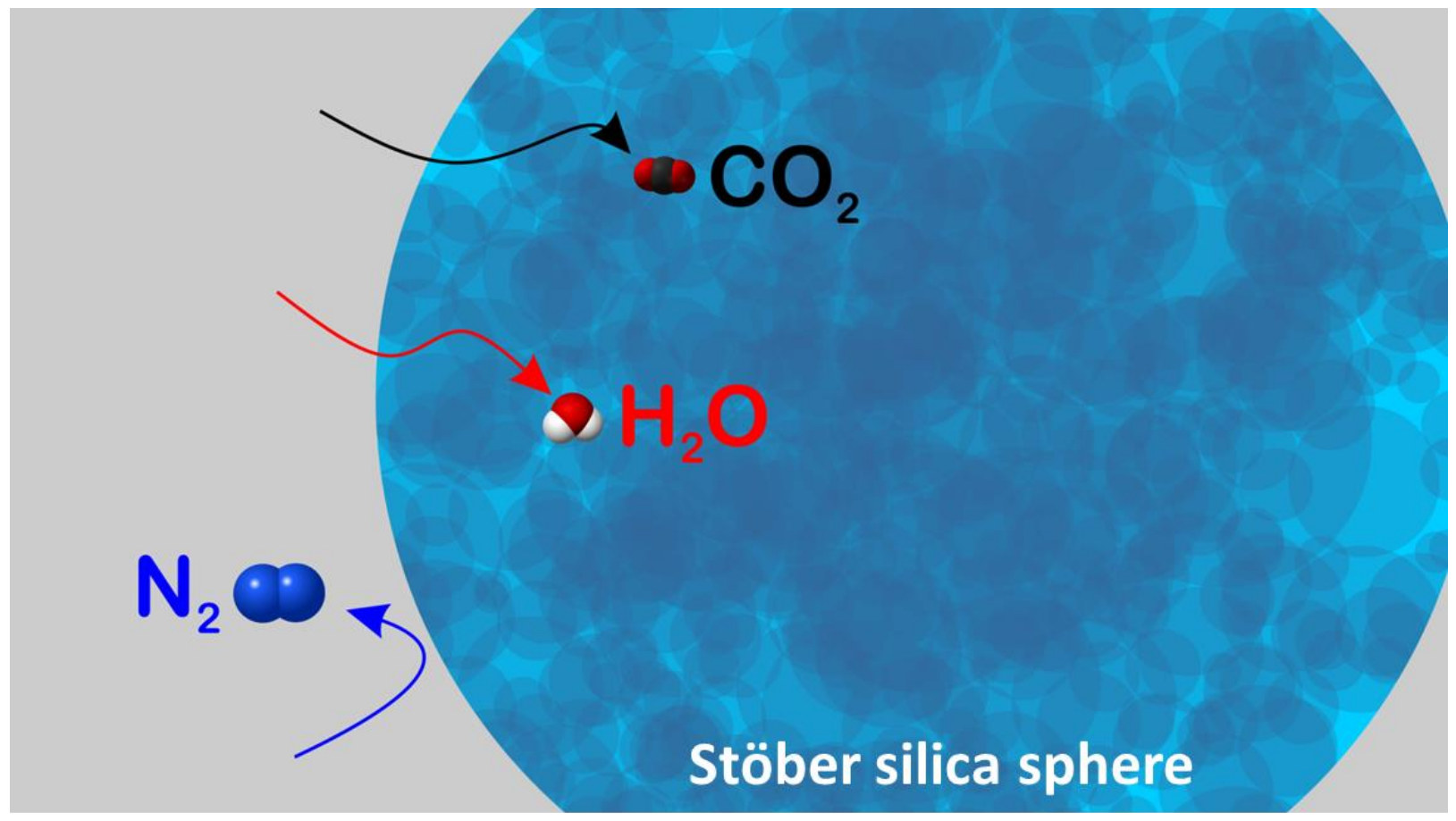

Microporosity of Stöber silica spheres is directly assessed and quantified by $\mathrm{CO}_{2}$ and water isotherms at 273 and $298 \mathrm{~K}$, respectively. $\mathrm{N}_{2}$ adsorption isotherms at $77 \mathrm{~K}$ erroneously yield a negligible microporous volume because of the strong kinetic restriction for $\mathrm{N}_{2}$ molecules to access the inner porosity. Micro- and mesopore characteristics are studied and the location of water molecules as a function of the relative pressure is addressed.

\section{REFERENCES}

${ }^{1}$ Stöber, W.; Fink, A.; Bohn, E. Controlled Growth of Monodisperse Silica Spheres in the Micron Size Range. J. Colloid Interface Sci. 1968, 26, 62-69.

${ }^{2}$ Li, Y. S.; Li, B.; Han, N. Y.; Xu, B. J. Studies on a poly (styrene-divinylbenzene)encapsulated sub-micrometer sized organic-inorganic hybrid silica packing, its synthesis, some of its characteristics and applications. J. Chromatography A 2003,1021(1-2), 183-189. 
${ }^{3}$ Yang, M.; Wu, H.; Wu, H.; Huang, C.; Weng, W.; Chen, M.; Wan, H. Preparation and characterization of a highly dispersed and stable Ni catalyst with a microporous nanosilica support. RSC Adv. 2016, 6(84), 81237-81244.

4 Sahiner, N.; Yasar, A. O. A new application for colloidal silica particles: natural, environmentally friendly, low-cost, and reusable catalyst material for $\mathrm{H}_{2}$ production from $\mathrm{NaBH}_{4}$ methanolysis. Ind. Eng. Chem. Res. 2016, 55(43), 11245-11252.

${ }^{5}$ Lin, Y. S.; Haynes, C. L. Impacts of mesoporous silica nanoparticle size, pore ordering, and pore integrity on hemolytic activity. J. Amer. Chem. Soc. 2010, 132(13), 4834-4842.

${ }^{6}$ Lukowiak, A.; Lao, J.; Lacroix, J.; Nedelec, J. M. Bioactive glass nanoparticles obtained through sol-gel chemistry. Chem. Commun. 2013, 49(59), 6620-6622.

${ }^{7}$ Niu, Y.; Yu, M.; Hartono, S.B.; Yang, J.; Xu, H.; Zhang, H.; Zhang, J.; Zou, J.; Dexter, A.; Gu, W.; Yu, C. Nanoparticles mimicking viral surface topography for enhanced cellular delivery. Adv. Mater. 2013, 25(43), 6233-6237.

${ }^{8}$ Saikia, J.; Yazdimamaghani, M.; Hadipour Moghaddam, S. P.; Ghandehari, H. Differential protein adsorption and cellular uptake of silica nanoparticles based on size and porosity. ACS Appl. Mater. Interfaces 2016, 8(50), 34820-34832.

${ }^{9}$ Abbaraju, P.L.; Meka, A.K.; Song, H.; Yang, Y.; Jambhrunkar, M.; Zhang, J.; Xu, C.; Yu, M.; Yu, C. Asymmetric Silica Nanoparticles with Tunable Head-Tail Structures Enhance Hemocompatibility and Maturation of Immune Cells. J. Amer. Chem. Soc. 2017, 139(18), 63216328.

${ }^{10}$ Chen, Y.; Chen, H.; Guo, L.; He, Q.; Chen, F.; Zhou, J.; Feng, J.; Shi, J. Hollow/rattle-type mesoporous nanostructures by a structural difference-based selective etching strategy. ACS nano 2009, 4(1), pp.529-539. 
${ }^{11}$ Xu, Z.; Liu, S.; Kang, Y.; Wang, M. Glutathione-and pH-responsive nonporous silica prodrug nanoparticles for controlled release and cancer therapy. Nanoscale 2015, 7(13), 5859-5868.

${ }^{12}$ Fan L.; Josephson D. P.; Stein A. Colloidal assembly: the road from particles to colloidal molecules and crystals. Angew. Chem. Intern. Ed. 2011, 50(2), 360-388.

${ }^{13}$ Gallego-Gómez, F.; Morales, M.; Blanco, A; López, C. Tunable Visual Detection of Dew by Bare Artificial Opals. Adv. Funct. Mater. 2018, 28(21), 1800591.

${ }^{14}$ Walcarius A.; Despas, C.; Bessire, J. Molecular sieving with amorphous monodisperse silica beads, Microporous Mesoporous Mater. 1998, 23, 309-313.

${ }^{15}$ Despas, C.; Walcarius, A.; Bessiere, J. Influence of the base size and strength on the acidic properties of silica gel and monodispersed silica beads: Interest of impedance measurements for the in situ monitoring of the ionization process. Langmuir 1999, 15 (9), 3186-3196.

${ }^{16}$ Quan, W.; Ramsey C.; Baran Q. Thermal pretreatment of silica composite filler materials. J Thermal Analysis Calorimetry 2009, 99(1), 237-243.

${ }^{17}$ Wang, R.; Habib, E; Zhu, X.X. Synthesis of wrinkled mesoporous silica and its reinforcing effect for dental resin composites. Dental Mater. 2017, 33(10), 1139-1148.

${ }^{18}$ Gallego-Gómez, F.; Blanco, A.; Golmayo, D.; López, C. Nanostructuring of azomolecules in silica artificial opals for enhanced photoalignment. Adv. Funct. Mater. 2011, 21, 4109.

${ }^{19}$ Moreno, Y.P.; Cardoso, M.B.; Ferrão, M.F.; Moncada, E.A; Dos Santos, J.H.Z. Effect of $\mathrm{SiCl}_{4}$ on the preparation of functionalized mixed-structure silica from monodisperse sol-gel silica nanoparticles. Chem. Eng. J. 2016, 292, 233-245.

${ }^{20}$ Gallego-Gómez, F.; Ibisate, M.; Golmayo, D.; Palomares, F. J.; Herrera, M.; Hernández, J.; Molina, S. I.; Blanco, A.; López, C. Light emission from nanocrystalline Si inverse opals and controlled passivation by atomic layer deposited $\mathrm{Al}_{2} \mathrm{O}_{3}$. Adv. Mater. 2011, 23, 5219 . 
${ }^{21}$ Teng, Z.; Wang, S.; Su, X.; Chen, G.; Liu, Y.; Luo, Z.; Luo, W.; Tang, Y.; Ju, H.; Zhao, D.; Lu, G. Facile synthesis of yolk-shell structured inorganic-organic hybrid spheres with ordered radial mesochannels. Adv. Mater. 2014, 26(22), pp.3741-3747.

${ }^{22}$ Van Blaaderen, A.; Van Geest, J.; Vrij, A. Monodisperse Colloidal Silica Spheres from Tetraalkoxysilanes: Particle Formation and Growth Mechanism. J. Colloid Interface Sci. 1992, $154(2), 481-501$.

${ }^{23}$ Giesche H.; Synthesis of monodispersed silica powders I. Particle properties and reaction kinetics. J. Eur. Ceram. Soc. 1994, 14, 189-204.

${ }^{24}$ Huang, Y.; Pemberton, J. E. Synthesis of Uniform, Spherical Sub-100nm Silica Particles using a Conceptual Modification of the Classic LaMer Model. Colloids Surf. A 2010, 360 (1-3), $175-183$.

25 Burneau, A.; Humbert, B. Aggregative growth of silica from an alkoxysilane in a concentrated solution of ammonia. Colloids Surf. A 1993, 75, 111-121.

${ }^{26}$ Carcouet, C.; van de Put, M. W. P.; Mezari, B.; Magusin, P.; Laven, J.; Bomans, P. H. H.; Friedrich, H.; Esteves, A. C. C.; Sommerdijk, N.; van Benthem, R.; de With, G. Nucleation and Growth of Monodisperse Silica Nanoparticles. Nano Lett. 2014, 14 (3), 1433-1438.

${ }^{27}$ Bogush, G. H.; Tracy, M. A.; Zukoski, C. F. Preparation of Monodisperse Silica Particles Control of Size and Mass Fraction. J. Non-Cryst. Solids 1988, 104, 95-106.

${ }^{28}$ N. Plumeré , A. Ruff, B. Speiser, V. Feldmann , H. A. Mayer, Stöber silica particles as basis for redox modifications: Particle shape, size, polydispersity, and porosity. J. Colloid. Interface Sci. 2012, 368 , 208 .

${ }^{29}$ Zhao, B.; Tian, C.; Zhang, Y.; Tang, T.; Wang, F. Size control of monodisperse nonporous silica particles by seed particle growth. Particuology 2011, 9(3), 314-317. 
${ }^{30}$ Greasley, S.L.; Page, S.J.; Sirovica, S.; Chen, S.; Martin, R.A.; Riveiro, A.; Hanna, J.V.; Porter, A.E.; Jones, J.R. Controlling particle size in the Stöber process and incorporation of calcium. J. Colloid. Interface Sci. 2016, 469, 213-223.

${ }^{31}$ Kurdyukov, D.A.; Eurov, D.A.; Kirilenko, D.A.; Sokolov, V.V.; Golubev, V.G. Tailoring the size and microporosity of Stöber silica particles. Microporous Mesoporous Mater. 2018, 258, 205-210.

32 Jelinek, L.; Dong P.; Rojas-Pazos, C.; Taibi, H.; Kovats, E.S. Study of the Stoeber reaction. 1. Properties of colloidal silica spheres prepared via alkoxide hydrolysis. Langmuir 1992, 8, $2152-2164$.

${ }^{33}$ Van Helden, A. K.; Jansen, J. W. J.; Vrij, A. Preparation and characterization of spherical monodisperse silica dispersions in nonaqueous solvents. J. Colloid Interface Sci.1981, 81(2), 354-368.

34 Legrand, A.P.; Hommel, H.; Tuel, A.; Vidal, A.; Balard, H.; Papirer, E.; Levitz, P.; Czemichowski, M.; Erre, R.; Van-Damme, H.; Gallas, J.P.; Homidy, J.F.; Lavalley, J.C.; Barres, O.; Burneau A.; Grillet, Y. Hydroxyls of silica powders. Adv. Colloid Interface Sci. $1990,33,91$.

35 Davis, P. J.; Deshpande, R.; Smith, D. M.; Brinker, C. J.; Assink, R. A. Pore Structure Evolution in Silica Gel during Aging/Drying. IV. Varying Pore Fluid pH. J. Non-Cryst. Solids 1994, 167 (3), 295-306.

36 Thommes, M.; Kaneko, K.; Neimark, A.V.; Olivier, J.P.; Rodriguez-Reinoso, F.; Rouquerol, J.; Sing, K.S.W. Physisorption of gases, with special reference to the evaluation of surface area and pore size distribution (IUPAC Technical Report), Pure Appl.Chem. 2015, 87, 1051-1069 
37 Gallas, J. P.; Lavalley, J. C.; Burneau, A.; Barres, O. Comparative study of the surface hydroxyl groups of fumed and precipitated silicas. 4. Infrared study of dehydroxylation by thermal treatments. Langmuir 1991, 7 (6), 1235-1240.

${ }^{38}$ de Keizer, A.; van der Ent, E.M.; Koopal, L.K. Surface and volume charge densities of monodisperse porous silicas. Colloids Surf. A 1998, 142, 303.

39 Szekeres, M.; Toth, J.; Dekany, I. Specific Surface Area of Stober Silica Determined by Various Experimental Methods. Langmuir 2002, 18 (7), 2678-2685.

${ }^{40}$ Li, S. S.; Wan, Q.; H. Qin, Z.; Fu Y. H.; Gu, Y. T. Understanding Stöber silica’s pore characteristics measured by gas adsorption. Langmuir 2015, 31, 824-832.

${ }^{41}$ Labrosse, A.; Burneau, A. Characterization of Porosity of Ammonia Catalysed Alkoxysilane Silica. J. Non-Cryst. Solids 1997, 221 (2-3), 107-124.

${ }^{42}$ Peng, L.; Qisui, W.; Xi, L.; Chaocan, Z. Investigation of the States of Water and OH Groups on the Surface of Silica. Colloids Surf. A 2009, 334 (1-3), 112-115.

43 Filipovic, R.; Obrenovic, Z.; Stijepovic, I.; Nikolic, L. M.; Srdic, V. V. Synthesis of Mesoporous Silica Particles with Controlled Pore Structure. Ceram. Int. 2009, 35 (8), $3347-3353$.

${ }^{44}$ Li, S. S.; Wan, Q.; H. Qin, Z.; Fu Y. H.; Gu, Y. T. Unraveling the Mystery of Stöber Silica's Microporosity. Langmuir 2016, 32, 9180-9187.

${ }^{45}$ Burneau, A.; Barres, O.; Gallas, J. P.; Lavalley, J. C. Comparative study of the surface hydroxyl groups of fumed and precipitated silicas. 2. Characterization by infrared spectroscopy of the interactions with water. Langmuir 1990, 6, 1364-1372.

46 Gallego-Gómez, F.; Blanco, A.; López, C. In situ optical study of water sorption in silica colloidal crystals. J. Phys. Chem. C 2012, 116, 18222-18229. 
${ }^{47}$ Wells, J. D.; Koopal L. K.; de Keizer A. Monodisperse, nonporous, spherical silica particles. Colloids Surf. A 2000, 166, 171-176

48 Dekany, I.; Nemeth, J.; Szekeres M.; Schoonheydt, R. Surfacial, liquid sorption and monolayer-forming properties of hydrophilic and hydrophobic Stöber silica particles. Colloid Polym. Sci. 2003, 282, 1-6.

${ }^{49}$ Bell, N.C.; Minelli, C.; Tompkins, J.; Stevens, M.M.; Shard, A.G. Emerging techniques for submicrometer particle sizing applied to Stöber silica, Langmuir 2012, 28, 10860-10872.

${ }^{50}$ Romeis, S.; Paul, J.; Hanisch, M.; Marthala, V.R.R.; Hartmann, M.; Taylor, R.N.K.; Schmidt, J.; Peukert, W. Correlation of Enhanced strength and internal structure for heat-treated submicron Stöber silica particles, Part. Part. Syst. Charact. 2014, 31, 664-674.

51 Vacassy, R.; Flatt, R.J.; Hofmann, H.; Choi, K.S.; Singhy, R.K. Synthesis of microporous silica spheres. J. Colloid Interface Sci. 2000, 227, 302-315.

${ }^{52}$ Khalil, K.M.; Mahmoud, H.A.; Ali, T.T. Direct formation of thermally stabilized amorphous mesoporous $\mathrm{Fe}_{2} \mathrm{O}_{3} / \mathrm{SiO}_{2}$ nanocomposites by hydrolysis of aqueous iron (III) nitrate in sols of spherical silica particles. Langmuir 2008, 24(3), 1037-1043.

${ }^{53}$ Hai, N.H.; Grigoriants, I.; Gedanken, A. Converting Stöber silica and Mediterranean sand to high surface area silicon by a reaction under autogenic pressure at elevated temperatures. $J$. Phys. Chem. C 2009, 113(24), 10521-10526.

54 Roque-Malherbe, R.; Polanco-Estrella, R.; Marquez-Linares, F. Study of the interaction between silica surfaces and the carbon dioxide molecule. J. Phys. Chem. C 2010, 114, 1777317787.

55 Yu, T.; Malugin, A.; Ghandehari, H. Impact of silica nanoparticle design on cellular toxicity and hemolytic activity. ACS Nano 2011, 5(7), 5717-5728. 
${ }^{56}$ Diedrich, T.; Dybowska, A.; Schott, J.; Valsarni-Jones, E.; Oelkers, E. H. The Dissolution Rates of $\mathrm{SiO}_{2}$ Nanoparticles As a Function of Particle Size. Environ. Sci. Technol. 2012, 46 (9), 4909-4915.

${ }^{57}$ Cho, S.-H.; Park, S. Y.; Kim, C.; Choi, P.-P.; Park, J.-K. Stabilization of Monodispersed Spherical Silica Particles and Their Alignment with Reduced Crack Density. Colloids Surf. A 2014, 441, 354-359.

58 Bazuła, P.A.; Arnal, P.M.; Galeano, C.; Zibrowius, B.; Schmidt, W.; Schüth, F. Highly microporous monodisperse silica spheres synthesized by the Stöber process. Microporous Mesoporous Mater. 2014, 200, 317-325.

${ }^{59}$ Muster, T.H.; Prestidge, C.A.; Hayes, R.A. Water adsorption kinetics and contact angles of silica particles. Colloids Surf. A 2001, 176(2-3), 253-266.

${ }^{60}$ Balas, F.; Rodriguez-Delgado, M.; Otero-Arean, C.; Conde, F.; Matesanz, E.; Esquivias, L.; Ramirez-Castellanos, J.; Gonzalez-Calbet, J.; Vallet-Regi, M. Structural Characterization of Nanosized Silica Spheres. Solid State Sci. 2007, 9 (5), 351-356.

${ }^{61}$ Wu, Z.; Han, H.; Han, W.; Kim, B.; Ahn, K.H.; Lee, K. Controlling the hydrophobicity of submicrometer silica spheres via surface modification for nanocomposite applications. Langmuir 2007, 23(14), 7799-7803.

${ }^{62}$ Boon, N.; van Roij, R. Charge reversal of moisturous porous silica colloids by take-up of protons. J. Colloid Interface Sci.2012, 385 (1), 66-72.

${ }^{63}$ Gouveia, R. F.; Galembeck, F. Electrostatic charging of hydrophilic particles due to water adsorption. J. Amer. Chem. Soc. 2009, 131(32), 11381-11386. 
${ }^{64}$ Campen, R.K.; Pymer, A. K.; Nihonyanagi, S.; Borguet, E. Linking surface potential and deprotonation in nanoporous silica: Second harmonic generation and acid/base titration. J. Phys. Chem. C 2010, 114, 18465-18473.

${ }^{65}$ Gallego-Gómez, F.; Morales-Flórez, V.; Morales, M.; Blanco, A.; López, C. Colloidal crystals and water: Perspectives on liquid-solid nanoscale phenomena in wet particulate media. Adv. Colloid Interface Sci. 2016, 234, 142-160.

${ }^{66}$ Bardyshev, I. I.; Mokrushin, A. D.; Pribylov, A. A.; Samarov, E. N.; Masalov, V. M.; Karpov, I. A.; Emel'chenko, G. A. Porous structure of synthetic opals. Colloid J. 2006, 68(1), 20-25.

${ }^{67}$ Garcia-Santamaria, F.; Miguez, H.; Ibisate, M.; Meseguer, F.; Lopez, C. Refractive index properties of calcined silica submicrometer spheres. Langmuir 2012, 18(5), 1942-1944.

${ }^{68}$ Gallego-Gómez, F.; Blanco, A.; López, C. Exploration and exploitation of water in colloidal crystals. Adv. Mater. 2015, 27, 2686-2714.

${ }^{69}$ Gallego-Gómez, F.; Blanco, A.; Canalejas-Tejero, V.; Lopez, C. Water-dependent photonic bandgap in silica artificial opals. Small 2011, 7, 1838-1845.

${ }^{70}$ Rouquerol, F.; Rouquerol, J.; Sing, K. Adsorption by powders and porous solids, Academic Press, London, 1999.

${ }^{71}$ A. Silvestre-Albero, J.M. Juarez-Galán, J. Silvestre-Albero, F. Rodríguez-Reinoso, Lowpressure hysteresis in adsorption: an artifact?. J. Phys. Chem. C 2012, 116, 16652-16655.

${ }^{72}$ Rios, R. V.; Silvestre-Albero, J.; Sepulveda-Escribano, A.; Molina-Sabio, M.; RodriguezReinoso, F. Kinetic restrictions in the characterization of narrow microporosity in carbon materials. J. Phys. Chem C 2007, 111, 3803-3805 
73 Garrido, J.; Linares-Solano, A.; Martin-Martínez, J.M.; Molina-Sabio, M.; RodríguezReinoso, F.; Torregrosa, R. Use of nitrogen vs. carbon dioxide in the characterization of activated carbons. Langmuir 1987, 3, 76-81

74 Silvestre-Albero, J.; Silvestre-Albero, A.; Rodríguez-Reinoso, F.; Thommes, M. Physical characterization of activated carbons with narrow microporosity by nitrogen $(77.4 \mathrm{~K})$, carbon dioxide $(273 \mathrm{~K})$ and argon $(87.3 \mathrm{~K})$ adsorption in combination with immersion calorimetry. Carbon 2012, 50(9), 3128-3133.

75 Zhuravlev, L.T. Surface characterization of amorphous silica-a review of work from the former USSR. Colloids Surf. A 1993, 74(1), 71-90.

${ }^{76}$ Gallego-Gomez, F.; Blanco, A.; Golmayo, D.; Lopez, C. Three regimes of water adsorption in annealed silica opals and optical assessment. Langmuir

2011, 27, 13992.

77 Parnell, S. R.; Washington, A. L.; Parnell, A. J.; Walsh, A.; Dalgliesh, R. M.; Li, F.; Hamilton, W. A.; Prevost, S.; Fairclough, J. P. A., Pynn, R. Porosity of silica Stöber particles determined by spin-echo small angle neutron scattering. Soft Matter 2016, 12(21), 4709-4714.

${ }^{78}$ Woignier, T.; Primera, J.; Alaoui, A.; Etienne, P.; Despestis, F.; Calas-Etienne, S. Mechanical properties and brittle behavior of silica aerogels. Gels 2015, 1(2), 256-275.

${ }^{79}$ Iler R.K. The Chemistry of Silica (Wiley, New York, 1979).

${ }^{80}$ Burns, G.T.; Deng Q.; Field R.; Hahn J.R.; Lentz C.W. A Convenient Synthesis of Silylated Silica Xerogels. Chem. Mater. 1999, 11, 1275-1284.

${ }^{81}$ Burggraaf A.J. Fundamentals of membrane top-layer synthesis and processing, in: A.J. Burggraaf, L. Cot (Eds.), Fundamentals of Inorganic Membrane Science and Technology, Membrane Science and Technology Series, Vol. 4 (Elsevier, Amsterdam, 1996). 
${ }^{82}$ Harper R.J., Stifel G.R., Anderson R.B. Adsorption of gases on 4A synthetic zeolite. Can. J. Chem. 1969, 47(24), 4661-4670.

${ }^{83}$ Gallego-Gómez, F.; Morales-Flórez, V.; Blanco, A.; de la Rosa-Fox, N.; López, C. Waterdependent micromechanical and rheological properties of silica colloidal crystals studied by nanoindentation. Nano Lett. 2012, 12 (9), 4920-4924.

${ }^{84}$ Gallego-Gómez, F.; Blanco, A.; López, C. Photoinduced local heating in silica photonic crystals for fast and reversible switching. Adv. Mater. 2012, 24, 6204-6209. 